\title{
Anti-inflammatory effect of stem cells against spinal cord injury via regulating macrophage polarization
}

\author{
This article was published in the following Dove Press journal: \\ Journal of Neurorestoratology \\ 13 February 2017 \\ Number of times this article has been viewed
}

\section{Zhijian Cheng \\ Xijing $\mathrm{He}$}

Department of Orthopedics, The Second Affiliated Hospital of Xi'an Jiaotong University, Xi'an, Shaanxi, People's Republic of China
Correspondence: Xijing He

Department of Orthopedics, The Second Affiliated Hospital of Xi'an Jiaotong University, 157 West Five Road, 710004

Xi'an, Shaanxi, People's Republic of China

$\mathrm{Tel}+8613909266195$

Email xijing_h@vip.tom.com
Abstract: Spinal cord injury (SCI) is a traumatic event that involves not just an acute physical injury but also inflammation-driven secondary injury. Macrophages play a very important role in secondary injury. The effects of macrophages on tissue damage and repair after SCI are related to macrophage polarization. Stem cell transplantation has been studied as a promising treatment for SCI. Recently, increasing evidence shows that stem cells, including mesenchymal stem, neural stem/progenitor, and embryonic stem cells, have an anti-inflammatory capacity and promote functional recovery after SCI by inducing macrophages M1/M2 phenotype transformation. In this review, we will discuss the role of stem cells on macrophage polarization and its role in stem cell-based therapies for SCI.

Keywords: stem cells, macrophages, spinal cord injury, polarization

\section{Introduction}

According to the National Spinal Cord Injury Statistical Center, there are $\sim 54$ cases per million population or $\sim 17,000$ new cases of spinal cord injury (SCI) annually in the US. SCI usually results in the loss of neurons and axonal damage, leading to loss of functions. ${ }^{1}$ The pathology of SCI can be divided into two distinct phases. First is the acute physical injury, which involves compression and/or contusion to the spinal cord, resulting in axonal damage and tissue destruction. This is followed hours to days later by secondary injury mechanisms. ${ }^{2}$ These secondary injuries involve persistent inflammation, glial scar formation, demyelination of surrounding neurons, and substantial cellular death. ${ }^{3,4}$ Among all aspects of secondary injury, the inflammatory response is the major cause and leads to widespread cell damage and expansion of the lesion.

Macrophages accumulate within the epicenter of the injured spinal cord and play a very important role in neuroinflammation, which is the most important pathological process and affects the local microenvironment. ${ }^{5,6}$ With increasing evidence confirming that M1 and M1 macrophages have differential contributions to tissue damage and repair, reprogramming M1 macrophages to adopt the M2 or regulatory phenotype may be helpful for controlling and resolving inflammation after SCI. ${ }^{7}$ Stem cell transplantation is a promising candidate to treat SCI. ${ }^{8-12}$ Recent work showed that stem cells, such as mesenchymal stem cells (MSCs), ${ }^{13-15}$ neural stem/progenitor cells (NS/ PCs), ${ }^{16,17}$ and embryonic stem cells (ESCs), ${ }^{18-20}$ have immunoregulatory capacity and anti-inflammatory effects and could enhance functional improvement through inducing macrophages M1/M2 phenotype transformation post SCI. 
This review will discuss 1) the general feature of macrophages in response to SCI, 2) the phenotype and function of macrophages in SCI, and 3) the effects of stem cells on macrophage polarization and its role in stem cell-based therapies for SCI.

\section{Macrophage response to SCI Sources and distribution of macrophages after $\mathrm{SCl}$}

There are two types of macrophages, which participate in the inflammatory response after SCI, monocyte-derived macrophages and microglia-derived macrophages. After SCI, microglial cells are activated quickly within a few minutes and part of them differentiates into macrophages. Then, blood monocytes are recruited by chemokines and cytokines such as macrophage chemotactic protein 1 (MCP-1) to the injury area where they differentiate into macrophages 2-3 days postinjury and bone marrow (BM)-derived macrophages persist at the injury site indefinitely. ${ }^{21-25}$ Macrophages are the major inflammatory effector cells, and the dual role of macrophages during SCI is demonstrated by two different type of macrophages, classical macrophages M1 and alternative macrophages M2.

\section{Dual effect of macrophages after $\mathrm{SCl}$}

There are both positive and negative effects of macrophages on tissue repair and regeneration after SCI. On the one hand, some studies show that infiltrating macrophages have harmful effects. For example, the spinal cord mRNA levels of interleukin-1 $\beta$ (IL-1 $\beta$ ) increase 12 hours after SCI; ${ }^{26}$ 72 hours after injury treated with IL-1 receptor antagonist, the contusion-induced apoptosis was significantly reduced. ${ }^{27}$ This result showed that IL- $1 \beta$ is harmful to tissue at the early stage. Macrophages are the main source of IL-1 $\beta$. Popovich et $\mathrm{al}^{28}$ found that macrophage infiltration was markedly reduced and the hindlimb function was significantly improved after the experiment animals were treated with liposomeencapsulated clodronate to deplete peripheral macrophages. Meanwhile, behavioral recovery was paralleled with more myelinated axon and decreased cavitation and enhanced sprouting. On the other hand, there are some results indicating that macrophages may have beneficial effects on tissue repair. Macrophages were transplanted into adult rat-injured spinal cords and then the regrowing axons were detected in the adjacent spinal cord sections. ${ }^{29}$ The result indicates that activated macrophages at the injured site could provide a beneficial microenvironment, which is good for regeneration of sensory axons, possibly due to the release of transforming growth factor- $\beta$ (TGF- $\beta$ ). ${ }^{30}$ Mitrasinovic et $\mathrm{al}^{31}$ showed that macrophages/microglia, with increasing expression of the macrophage colony-stimulating factor receptor, have a protective effect on neurons subjected to excitotoxic and teratogen-induced injury, together with macrophage colonystimulating factor.

\section{Macrophage polarization and SCI Macrophage phenotype}

The opposite effects of macrophages on the pathological process of SCI may be due to different phenotypes of macrophages. There are two main subsets of macrophages, M1 (classical activation) and M2 (alternative activation). ${ }^{32}$

Classical activation involves the induction of M1 macrophages by toll-like receptor (TLR) ligands or proinflammatory cytokines, such as interferon- $\gamma($ IFN- $\gamma)$. These cells produce high levels of oxidative metabolites (e.g., superoxide and nitric oxide), inducible nitric oxide synthase (iNOS), chemokine (C-C motif) ligand 12 (CCL12), and proinflammatory molecules such as tumor necrosis factor- $\alpha$ (TNF- $\alpha)$, IL-1 $\beta$, interleukin-6 (IL-6), and interleukin-12 (IL-12) that are essential for host defense and tumor cell killing but that also cause damage to healthy cells/tissue. ${ }^{33-37}$

M2 macrophages are characterized by expression of Ym1, arginase-1 (Arg-1), CD206, CD209, and IL-1 receptor antagonist (IL-1Ra), found in inflammatory zone 1 (FIZZ1) and mannose receptor, and based on their high production of anti-inflammatory cytokines such as IL-12 and low production of proinflammatory cytokines such as IL-1 $\beta$ and IL-12. These cells also have high phagocytic activities. ${ }^{38-44}$ The differentiation of M2 macrophages is promoted by different molecules such as IL-4, IL-6, IL-10, IL-13, vascular endothelial growth factor, and prostaglandin E2 (PGE2). M2 macrophages play a major role in resolving inflammation, degrading scar, and remodeling tissue by secreting trophic factors and releasing IL-10. ${ }^{45}$ M2-polarized macrophages can be further divided into M2a (promoted by IL-4 or IL-13), ${ }^{44,46}$ M2b (elicited by immune complexes in the presence of a TLR ligand), ${ }^{47}$ and M2c (following stimulation by anti-inflammatory factors such as glucocorticoid hormones, IL-10, and TGF- $\beta$ ). ${ }^{48,49}$

\section{Macrophage polarization after SCl}

Genes associated with M1 and M2 macrophages detected by cDNA microarrays were rapidly induced in the injured spinal cord. M1 gene expression maintained for up to 1 month after SCI. However, the expression of M2 genes was transient and returned to preinjury levels by 7 days post-SCI. Meanwhile, the immunofluorescence staining result showed that CD86positive M1 macrophages and Arg-1 (a typical marker of 
M2 macrophages)-positive macrophages coexisted within injury site at 3 days after SCI, but only M1 macrophages had persisted until 28 days postinjury. The expression of Arg-1 returned to normal level 7 days after SCI. ${ }^{50}$ Therefore, it is well known that the rapid response and maintenance of M1 and the transient existence of M2 at the injured spinal cord area lead to the secondary damage. ${ }^{51}$ In rat, the adoptive polarization of macrophage to M2 is beneficial for facilitating the recovery after SCI. ${ }^{52}$

Following SCI, macrophages express cytokines such as TNF- $\alpha$, IL- $1 \beta$ and IL- 6 and chemokines including CCL8, CCL15, and CXCL9 to alter macrophage phenotype to M1. ${ }^{53}$ At the same time, IFN- $\gamma$ released by Type $1 \mathrm{~T}$ helper (Th1) cells, microglia, and astrocytes plays a very important role in macrophage polarization. This indicates that macrophages could be polarized in both autocrine and paracrine manners. Kigerl et $\mathrm{l}^{50}$ found that $\mathrm{M} 2$ macrophage response was very short and returned to the level of normal spinal cord. When BM-derived M2 macrophages with fluorescent dye were injected into injury site, the number of M2 macrophages was reduced by $20-40 \%$, while the number of M2 macrophages transplanted into the normal spinal cord almost did not change. ${ }^{50}$ So the microenvironment after SCI is more likely to induce macrophages to M1 cells and keep M1 state of macrophages.

Macrophage polarization in CNS injury could be affected by many factors, such as reactive oxygen species (ROS) and chondroitin sulfate proteoglycan. ${ }^{54,55}$ For example, macrophage polarization is influenced by the degree of injury. chondroitin sulfate proteoglycans (GSPGs), a major component of the glial scar, is considered to be a major obstacle for tissue recovery after injury. GSPGs directly activated macrophages via the CD44 receptor and promoted M2 macrophage polarization after SCI. ${ }^{55}$ Myelin debris may be an associated factor switching the macrophage phenotype from M2 to M1. ${ }^{56}$ In addition, ROS are involved in the activation process of M1 macrophages partly by nuclear factor-kappa light-chain-enhancer of activated B cells (NF-kB) pathway. It still needs further study to understand how ROS, resulting from SCI, regulate the polarization of macrophages. ${ }^{57,58}$

\section{Phenotype-specific roles of macrophages in $\mathrm{SCl}$ repair and regeneration Oligodendrogenesis and remyelination}

Recent studies indicate that M2 macrophages are important for efficient remyelination after CNS injury. During the relapsing phase of experimental autoimmune encephalomyelitis, there is an M1-dominant phenotype, while a dominant M2 response at the lesion site is observed in the remyelination phase. ${ }^{59}$ Meanwhile, oligodendrocyte differentiation is also affected by macrophages. Conditional medium from M2 macrophages enhances the differentiation of NS/PCs into oligodendrocytes in vitro, but oligodendrocyte differentiation was significantly blocked by M1 macrophages via a TNF- $\alpha$-dependent mechanism. ${ }^{59}$ Further, M1 macrophageconditioned medium was found to aggravate oxygen glucose deprivation (OGD)-induced oligodendrocyte death, whereas M2 macrophages protected oligodendrocyte from OGD. ${ }^{60,61}$

\section{Neurogenesis}

Macrophages also exert opposite effects on neurogenesis after injury. Proinflammatory M1 macrophages hinder neurogenesis by secreting destructive factors including IL-1 $\beta$, IFN- $\gamma$, and TNF- $\alpha$ and aggravate long-term neurological deficits after injury. ${ }^{48,62}$ In contrast, M2 microglia/macrophages promote basal neurogenesis. ${ }^{63,64}$ Therefore, M1 and M2 macrophages have distinct effects on neurogenesis.

\section{Axonal regeneration}

Kitayama et al ${ }^{65}$ show that M1 microglia/macrophages that are activated by lipopolysaccharide could inhibit neurite outgrowth and induce growth cone collapse of cortical neurons. M1 macrophages could also induce axonal retraction in adult dorsal root ganglion neuron through physical cell-cell interactions. On the other hand, M2 macrophages are critical for axonal regeneration. ${ }^{66}$ Cytokines such as IL-10 secreted by M2 macrophages could promote axonal regrowth and functional recovery after SCI. ${ }^{67}$ Taken together, M1 macrophages can block axonal regeneration. ${ }^{65,68}$

\section{Effects of stem cells on polarization after SCl}

Thus, polarization of macrophages to $\mathrm{M} 2$ is beneficial to facilitate the recovery after SCI. Recently, stem cell transplantation has been demonstrated to have a tremendous therapeutic promise by several different mechanisms. Stem cells, such as MSCs, NS/PCs, and ESCs, are multipluripotent cells existing in both embryonic and adult tissues. They have the capacity for asymmetric cell division and enhanced proliferation. Increasing evidence shows that stem cells have immunoregulatory capacity and promote functional recovery through regulating macrophage polarization. ${ }^{69}$

\section{MSCs and macrophage polarization}

MSCs represent a heterogeneous population of multipotent cells and are capable of secreting growth factor and differentiating into mesodermal, endodermal, and even ectodermal cells under appropriate culture conditions. ${ }^{70} \mathrm{MSCs}$ do not form teratoma and are safe for tissue regeneration and repair. MSCs possess the 
immunomodulatory capacity to induce regulatory $\mathrm{T}$ cells, ${ }^{71,72}$ regulate the differentiation and function of dendritic cells, ${ }^{73}$ and inhibit lymphocyte proliferation. ${ }^{74,75}$ Recently, it has become clear that MSCs also regulate the function and activation of macrophages. ${ }^{76-79}$ There is a large body of evidence demonstrating that the effects of MSCs on macrophages are critical for inflammatory response and tissue repair after SCI. ${ }^{80-84}$

Nakajima et al observed that BM-MSCs altered macrophages into anti-inflammatory $\mathrm{M} 2$ and beneficially modulated the immune system. ${ }^{80}$ When human BM-derived macrophages were cocultured with human BM-MSCs, these macrophages showed high expression of a well-known marker of alternatively activated M2 macrophages (CD206) and expressed low levels of TNF- $\alpha$ and IL-12 and high levels of IL-6 and IL-10. ${ }^{85}$ And macrophages cocultured with MSCs showed increased phagocytic activity. Mouse BM-MSCs also had similar effects on macrophages. ${ }^{86}$ Cho et al ${ }^{87}$ also found that the M1 markers including IL-1 $\beta$, IL-6, and iNOS of macrophages were significantly reduced, but the M2 markers such as Arg-1, IL-10, and CD206 of macrophages were markedly upregulated by treating with mouse BM-MSCs.

MSCs modulate macrophages to adapt a regulatory phenotype by cell contact and production of immunomodulatory and growth factors. The production of PGE-2 secreted by MSCs plays an important role in induction of MSC-educated macrophages. ${ }^{86}$ Acetylsalicylic acid, a cyclooxygenase inhibitor, can impair the effects of MSCs on macrophages. In addition, Cao et $\mathrm{al}^{88}$ found that M2 macrophages were recruited by the transplanted MSCs in a stromal cell-derived factor 1 (SDF-1)-dependent manner. A previous study showed that MSCs skewed macrophages toward an M2 phenotype through inhibiting NF- $\mathrm{KB}$ and activating STAT3. ${ }^{89}$ Recent research has shown, exosomes have been implicated in many aspects of immune regulation. ${ }^{90} \mathrm{MSC}$ s exosomes have regulatory abilities for macrophage polarization and induce an antiinflammatory M2-like phenotype via shuttling let-7b. ${ }^{91,92}$

Besides BM, MSCs can be isolated from adipose tissues, lung, gingiva, placenta, liver, cord blood, and umbilical cord. ${ }^{93-96}$ There are some similar experiments showing that MSCs from the other tissues also can polarize macrophages to the alternatively activated M2 phenotype. In parallel observation with human placental MSCs, Abumaree et $\mathrm{al}^{97}$ also found that the human placental MSCs also have potent anti-inflammatory and immunosuppressive actions via converting macrophages from a proinflammatory M1 phenotype to an anti-inflammatory M2 phenotype. At the same time, human gingiva-derived MSCs also have the same effects on the phenotype of macrophages.
More studies indicate that grafted MSCs significantly improve functional recovery in animal models of SCI by providing neural protection and support and angiogenic stimulation. ${ }^{98}$ Nakajima et $a l^{80}$ reported the activation of macrophages in the inflammatory environment after SCI was regulated by the grafted human MSCs. Transplantation of human undifferentiated MSCs after SCI promoted functional recovery and modified inflammatory environment by shifting the macrophages phenotype from M1 to M2 and increasing the levels of IL-13 and IL-4 and reducing the levels of IL- 6 and TNF- $\alpha$. With the alteration of macrophages phenotype, less scar tissue formation, increased myelin sparing, and more preserved axons were observed in MSC-transplanted group. Furthermore, there were no transplanted MSCs in the injured spinal cord differentiating into neurons, astrocytes, or oligodendrocytes. Therefore, MSCs suppress inflammation and enhance tissue repair by polarizing macrophages to the alternatively activated M2 phenotype after SCI.

\section{NS/PCs and macrophage polarization}

NS/PCs are capable of self-renewal and generating the main phenotypes of CNS cells. Transplantation of NS/PCs is promising treatment for SCI ${ }^{99-103} \mathrm{NS} / \mathrm{PCs}$ usual has been studied as a mean to replace the damaged neurons in SCI. However, increasing data showed that NSCs can promote motor functional recovery by modulating the host environment.

Cusimano et $\mathrm{al}^{104}$ found that the transplantation of mouse NS/PCs only at the subacute phase of SCI could enhance the recovery of locomotor functions of mice with SCI. These cells skewed the inflammatory cell infiltrated in the injured area by reducing the proportion of M1 macrophages and promoted the injured spinal cord regeneration and repair. However, Nishimura et $\mathrm{l}^{105}$ found that the transplantation of NS/PCs only at the subacute phase of SCI promotes functional recovery. Our unpublished data demonstrated that NSC-conditioned medium can reduce the expression of iNOS within the spinal cord and spleen of injured animals, indicating an ability to reduce systemic inflammation. Meanwhile, multipotent adult progenitor cells also induce a shift in macrophages from an M1 state to an M2 state, prevent macrophage-mediated axonal dieback, and promote regrowth after SCI. ${ }^{106}$

\section{Embryonic stem cells}

ESCs are a kind of pluripotent stem cell that can be derived from the inner cells mass of the early embryo. ESCs can restore function following transplantation into paralyzed rats. ${ }^{18,107}$ Bottai et 
a ${ }^{18}$ injected undifferentiated ESCs through the tail vein 2 hours post-SCI and the Basso Beattie Bresnahan scores of ESCs transplantation group were significantly increased compared with the control group. The data in the same report showed that the number of invading neutrophils and macrophages was greatly reduced, and ESC transplantation may improve functional recovery through this inflammation inhibition effect. The other article reports that the level of TNF- $\alpha$ in injured spinal cord significantly decreases, and the inflammation following SCI is inhibited by ESCs transplantation. ESCs can recruit macrophage by secreting molecules, such as MCP-1 and Matrix metallopeptidase-9. ${ }^{108}$ In addition, ESCs promote macrophage survival and polarize macrophages toward an M2-like phenotype by releasing factors such as IL-34 and activating STAT3 and STAT6 signaling pathways. ${ }^{109}$ Transplanted ESCs may form teratomas, which are constituted by cells from endodermal, mesodermal, and ectodermal lineages. ${ }^{110-112}$ Recently, Guo et $\mathrm{al}^{113}$ show that ESC-conditioned media can effectively reduce lipid accumulation, promote an M2-like state, and improve functional recovery after SCI. ESC-conditioned medium is sufficient to promote functional recovery in a murine model of SCI and avoids teratoma formation.

\section{Conclusion}

Accumulating evidence suggests that the bias of M2 macrophages over M1 macrophages is highly correlated with the remission of SCI that was clearly augmented in cases receiving SCI interventions, including anti-inflammatory therapies and stem cells. Stem cells can alter the macrophage polarization and promote functional recovery postinjury. But the mechanism by which stem cells regulate macrophage polarization remains to be determined.

\section{Disclosure}

The authors report no conflicts of interest in this work.

\section{References}

1. Devivo MJ. Epidemiology of traumatic spinal cord injury: trends and future implications. Spinal Cord. 2012;50(5):365-372.

2. Oyinbo CA. Secondary injury mechanisms in traumatic spinal cord injury: a nugget of this multiply cascade. Acta Neurobiol Exp (Wars). 2011;71(2):281-299.

3. Zhang N, Yin Y, Xu SJ, Wu YP, Chen WS. Inflammation \& apoptosis in spinal cord injury. Indian J Med Res. 2012;135:287-296.

4. Benowitz LI, Popovich PG. Inflammation and axon regeneration. Curr Opin Neurol. 2011;24(6):577-583.

5. Fehlings MG, Nguyen DH. Immunoglobulin G: a potential treatment to attenuate neuroinflammation following spinal cord injury. $J$ Clin Immunol. 2010;30(suppl 1):S109-S112.

6. Zhang YK, Liu JT, Peng ZW, et al. Different TLR4 expression and microglia/macrophage activation induced by hemorrhage in the rat spinal cord after compressive injury. J Neuroinflammation. 2013;10:112.
7. Ren Y, Young W. Managing inflammation after spinal cord injury through manipulation of macrophage function. Neural Plast. 2013;2013:945034.

8. Kumagai G, Okada Y, Yamane J, et al. Roles of ES cell-derived gliogenic neural stem/progenitor cells in functional recovery after spinal cord injury. PLoS One. 2009;4(11):e7706.

9. Chen J, Bernreuther C, Dihne M, Schachner M. Cell adhesion molecule 11-transfected embryonic stem cells with enhanced survival support regrowth of corticospinal tract axons in mice after spinal cord injury. J Neurotrauma. 2005;22(8):896-906.

10. Yan-Wu G, Yi-Quan K, Ming L, et al. Human umbilical cord-derived Schwann-like cell transplantation combined with neurotrophin-3 administration in dyskinesia of rats with spinal cord injury. Neurochem Res. 2011;36(5):783-792.

11. Webber DJ, Bradbury EJ, McMahon SB, Minger SL. Transplanted neural progenitor cells survive and differentiate but achieve limited functional recovery in the lesioned adult rat spinal cord. Regen Med. 2007;2(6):929-945.

12. Wu MC, Yuan H, Li KJ, Qiu DL. Cellular transplantation-based evolving treatment options in spinal cord injury. Cell Biochem Biophys. 2015;71(1):1-8.

13. Zhang YJ, Zhang W, Lin CG, et al. Neurotrophin-3 gene modified mesenchymal stem cells promote remyelination and functional recovery in the demyelinated spinal cord of rats. J Neurol Sci. 2012;313(1-2):64-74.

14. Park WB, Kim SY, Lee SH, Kim HW, Park JS, Hyun JK. The effect of mesenchymal stem cell transplantation on the recovery of bladder and hindlimb function after spinal cord contusion in rats. BMC Neurosci. 2010;11:119.

15. Zhang R, Liu Y, Yan K, et al. Anti-inflammatory and immunomodulatory mechanisms of mesenchymal stem cell transplantation in experimental traumatic brain injury. $J$ Neuroinflammation. 2013; 10(1): 106 .

16. Yang J, Yan Y, Xia Y, et al. Neurotrophin 3 transduction augments remyelinating and immunomodulatory capacity of neural stem cells Mol Ther. 2014;22(2):440-450.

17. Liu SJ, Zou Y, Belegu V, et al. Co-grafting of neural stem cells with olfactory en sheathing cells promotes neuronal restoration in traumatic brain injury with an anti-inflammatory mechanism. J Neuroinflammation. 2014;11:66

18. Bottai D, Cigognini D, Madaschi L, et al. Embryonic stem cells promote motor recovery and affect inflammatory cell infiltration in spinal cord injured mice. Exp Neurol. 2010;223(2):452-463.

19. Cui YF, Xu JC, Hargus G, Jakovcevski I, Schachner M, Bernreuther C. Embryonic stem cell-derived L1 overexpressing neural aggregates enhance recovery after spinal cord injury in mice. PLoS One. 2011;6(3):e17126.

20. Zhang K, Zheng J, Bian G, et al. Polarized macrophages have distinct roles in the differentiation and migration of embryonic spinal-cordderived neural stem cells after grafting to injured sites of spinal cord. Mol Ther. 2015;23(6):1077-1091.

21. Boring L, Gosling J, Chensue SW, et al. Impaired monocyte migration and reduced type 1 (Th1) cytokine responses in C-C chemokine receptor 2 knockout mice. J Clin Invest. 1997;100(10):2552-2561.

22. Crane MJ, Hokeness-Antonelli KL, Salazar-Mather TP. Regulation of inflammatory monocyte/macrophage recruitment from the bone marrow during murine cytomegalovirus infection: role for type I interferons in localized induction of CCR2 ligands. J Immunol. 2009;183(4):2810-2817.

23. Jones GE. Cellular signaling in macrophage migration and chemotaxis. J Leukoc Biol. 2000;68(5):593-602.

24. Pixley FJ. Macrophage migration and its regulation by CSF-1. Int $J$ Cell Biol. 2012;2012:501962.

25. Webb SE, Pollard JW, Jones GE. Direct observation and quantification of macrophage chemoattraction to the growth factor CSF-1. J Cell Sci. 1996;109(pt 4):793-803.

26. Pineau I, Lacroix S. Proinflammatory cytokine synthesis in the injured mouse spinal cord: multiphasic expression pattern and identification of the cell types involved. J Comp Neurol. 2007;500(2):267-285. 
27. Boato F, Rosenberger K, Nelissen S, et al. Absence of IL-1beta positively affects neurological outcome, lesion development and axonal plasticity after spinal cord injury. J Neuroinflammation. 2013;10:6.

28. Popovich PG, Guan Z, Wei P, Huitinga I, van Rooijen N, Stokes BT. Depletion of hematogenous macrophages promotes partial hindlimb recovery and neuroanatomical repair after experimental spinal cord injury. Exp Neurol. 1999;158(2):351-365.

29. Prewitt CM, Niesman IR, Kane CJ, Houle JD. Activated macrophage/ microglial cells can promote the regeneration of sensory axons into the injured spinal cord. Exp Neurol. 1997;148(2):433-443.

30. Kiefer R, Lindholm D, Kreutzberg GW. Interleukin- 6 and transforming growth factor-beta $1 \mathrm{mRNAs}$ are induced in rat facial nucleus following motoneuron axotomy. Eur J Neurosci. 1993;5(7):775-781.

31. Mitrasinovic OM, Grattan A, Robinson CC, et al. Microglia overexpressing the macrophage colony-stimulating factor receptor are neuroprotective in a microglial-hippocampal organotypic coculture system. J Neurosci. 2005;25(17):4442-4451.

32. Silver J, Schwab ME, Popovich PG. Central nervous system regenerative failure: role of oligodendrocytes, astrocytes, and microglia. Cold Spring Harb Perspect Biol. 2015;7(3):a020602.

33. Akiyama $\mathrm{H}$, Barger $\mathrm{S}, \mathrm{Barnum} \mathrm{S}$, et al. Inflammation and Alzheimer's disease. Neurobiol Aging. 2000;21(3):383-421.

34. Brown GC. Mechanisms of inflammatory neurodegeneration: iNOS and NADPH oxidase. Biochem Soc Trans. 2007;35(pt 5):1119-1121.

35. Bellora F, Castriconi R, Dondero A, et al. The interaction of human natural killer cells with either unpolarized or polarized macrophages results in different functional outcomes. Proc Natl Acad Sci USA. 2010;107(50): 21659-21664.

36. Gordon S, Taylor PR. Monocyte and macrophage heterogeneity. Nat Rev Immunol. 2005;5(12):953-964.

37. Galzie Z. Structure and function of human and murine receptors for IgG. Indian J Biochem Biophys. 1991;28(2):77-82.

38. Simmons D, Seed B. The Fc gamma receptor of natural killer cells is a phospholipid-linked membrane protein. Nature. 1988;333(6173):568-570.

39. Ezekowitz RA, Sastry K, Bailly P, Warner A. Molecular characterization of the human macrophage mannose receptor: demonstration of multiple carbohydrate recognition-like domains and phagocytosis of yeasts in Cos-1 cells. J Exp Med. 1990;172(6):1785-1794.

40. Law SK, Micklem KJ, Shaw JM, et al. A new macrophage differentiation antigen which is a member of the scavenger receptor superfamily. Eur J Immunol. 1993;23(9):2320-2325.

41. Relloso M, Puig-Kroger A, Pello OM, et al. DC-SIGN (CD209) expression is IL-4 dependent and is negatively regulated by IFN, TGF-beta, and anti-inflammatory agents. J Immunol. 2002;168(6):2634-2643.

42. Menzies FM, Henriquez FL, Alexander J, Roberts CW. Sequential expression of macrophage anti-microbial/inflammatory and wound healing markers following innate, alternative and classical activation. Clin Exp Immunol. 2010;160(3):369-379.

43. Komori T, Morikawa Y, Inada T, Hisaoka T, Senba E. Site-specific subtypes of macrophages recruited after peripheral nerve injury. Neuroreport. 2011;22(17):911-917.

44. Varnum MM, Ikezu T. The classification of microglial activation phenotypes on neurodegeneration and regeneration in Alzheimer's disease brain. Arch Immunol Ther Exp (Warsz). 2012;60(4): 251-266.

45. Shechter R, Miller O, Yovel G, et al. Recruitment of beneficial M2 macrophages to injured spinal cord is orchestrated by remote brain choroid plexus. Immunity. 2013;38(3):555-569.

46. Ahn M, Lee C, Jung K, et al. Immunohistochemical study of arginase-1 in the spinal cords of rats with clip compression injury. Brain Res. 2012;1445:11-19.

47. Mantovani A, Sica A, Sozzani S, Allavena P, Vecchi A, Locati M. The chemokine system in diverse forms of macrophage activation and polarization. Trends Immunol. 2004;25(12):677-686.

48. Ekdahl CT, Claasen JH, Bonde S, Kokaia Z, Lindvall O. Inflammation is detrimental for neurogenesis in adult brain. Proc Natl Acad Sci $U$ S A. 2003;100(23):13632-13637.
49. Kiyota T, Okuyama S, Swan RJ, Jacobsen MT, Gendelman HE, Ikezu T. CNS expression of anti-inflammatory cytokine interleukin-4 attenuates Alzheimer's disease-like pathogenesis in APP+PS1 bigenic mice. FASEB J. 2010;24(8):3093-3102.

50. Kigerl KA, Gensel JC, Ankeny DP, Alexander JK, Donnelly DJ, Popovich PG. Identification of two distinct macrophage subsets with divergent effects causing either neurotoxicity or regeneration in the injured mouse spinal cord. J Neurosci. 2009;29(43):13435-13444.

51. Shakhbazau A, Mishra M, Chu TH, et al. Fluorescent phosphorus dendrimer as a spectral nanosensor for macrophage polarization and fate tracking in spinal cord injury. Macromol Biosci. 2015;15(11):1523-1534.

52. Gensel JC, Zhang B. Macrophage activation and its role in repair and pathology after spinal cord injury. Brain Res. 2015;1619:1-11.

53. David S, Kroner A. Repertoire of microglial and macrophage responses after spinal cord injury. Nat Rev Neurosci. 2011;12(7):388-399.

54. Hu X, Li P, Guo Y, et al. Microglia/macrophage polarization dynamics reveal novel mechanism of injury expansion after focal cerebral ischemia. Stroke. 2012;43(11):3063-3070.

55. Rolls A, Shechter R, London A, et al. Two faces of chondroitin sulfate proteoglycan in spinal cord repair: a role in microglia/macrophage activation. PLoS Med. 2008;5(8):e171.

56. Wang X, Cao K, Sun X, et al. Macrophages in spinal cord injury: phenotypic and functional change from exposure to myelin debris. Glia. 2015;63(4):635-651.

57. Tan HY, Wang N, Li S, Hong M, Wang X, Feng Y. The reactive oxygen species in macrophage polarization: reflecting its dual role in progression and treatment of human diseases. Oxid Med Cell Longev. 2016;2016:2795090.

58. Brune B, Dehne N, Grossmann N, et al. Redox control of inflammation in macrophages. Antioxid Redox Signal. 2013;19(6):595-637.

59. Miron VE, Boyd A, Zhao JW, et al. M2 microglia and macrophages drive oligodendrocyte differentiation during CNS remyelination. Nat Neurosci. 2013;16(9):1211-1218.

60. Wang G, Zhang J, Hu X, et al. Microglia/macrophage polarization dynamics in white matter after traumatic brain injury. J Cereb Blood Flow Metab. 2013;33(12):1864-1874.

61. Wang G, Shi Y, Jiang X, et al. HDAC inhibition prevents white matter injury by modulating microglia/macrophage polarization through the GSK3beta/PTEN/Akt axis. Proc Natl Acad Sci U S A. 2015;112(9):2853-2858.

62. Roughton K, Andreasson U, Blomgren K, Kalm M. Lipopolysaccharide-induced inflammation aggravates irradiation-induced injury to the young mouse brain. Dev Neurosci. 2013;35(5):406-415.

63. Butovsky O, Ziv Y, Schwartz A, et al. Microglia activated by IL-4 or IFN-gamma differentially induce neurogenesis and oligodendrogenesis from adult stem/progenitor cells. Mol Cell Neurosci. 2006;31(1):149-160.

64. Nikolakopoulou AM, Dutta R, Chen Z, Miller RH, Trapp BD. Activated microglia enhance neurogenesis via trypsinogen secretion. Proc Natl Acad Sci U S A. 2013;110(21):8714-8719.

65. Kitayama M, Ueno M, Itakura T, Yamashita T. Activated microglia inhibit axonal growth through RGMa. PLoS One. 2011;6(9):e25234.

66. Shechter R, London A, Varol C, et al. Infiltrating blood-derived macrophages are vital cells playing an anti-inflammatory role in recovery from spinal cord injury in mice. PLoS Med. 2009;6(7):e1000113.

67. Kwon MJ, Kim J, Shin H, et al. Contribution of macrophages to enhanced regenerative capacity of dorsal root ganglia sensory neurons by conditioning injury. $J$ Neurosci. 2013;33(38):15095-15108.

68. Horn KP, Busch SA, Hawthorne AL, van Rooijen N, Silver J. Another barrier to regeneration in the CNS: activated macrophages induce extensive retraction of dystrophic axons through direct physical interactions. $J$ Neurosci. 2008;28(38):9330-9341.

69. Nazmi A, Mohamed Arif I, Dutta K, Kundu K, Basu A. Neural stem/progenitor cells induce conversion of encephalitogenic $\mathrm{T}$ cells into CD4+-CD25+-FOXP3+ regulatory T cells. Viral Immunol. 2014;27(2):48-59. 
70. Pittenger MF, Mackay AM, Beck SC, et al. Multilineage potential of adult human mesenchymal stem cells. Science. 1999;284(5411):143-147.

71. Ge W, Jiang J, Baroja ML, et al. Infusion of mesenchymal stem cells and rapamycin synergize to attenuate alloimmune responses and promote cardiac allograft tolerance. Am J Transplant. 2009;9(8):1760-1772.

72. Aggarwal S, Pittenger MF. Human mesenchymal stem cells modulate allogeneic immune cell responses. Blood. 2005;105(4):1815-1822.

73. Nauta AJ, Kruisselbrink AB, Lurvink E, Willemze R, Fibbe WE. Mesenchymal stem cells inhibit generation and function of both CD34+-derived and monocyte-derived dendritic cells. J Immunol. 2006;177(4):2080-2087.

74. Meisel R, Zibert A, Laryea M, Gobel U, Daubener W, Dilloo D. Human bone marrow stromal cells inhibit allogeneic T-cell responses by indoleamine 2,3-dioxygenase-mediated tryptophan degradation. Blood. 2004;103(12):4619-4621.

75. Di Nicola M, Carlo-Stella C, Magni M, et al. Human bone marrow stromal cells suppress T-lymphocyte proliferation induced by cellular or nonspecific mitogenic stimuli. Blood. 2002;99(10):3838-3843.

76. Lee KC, Lin HC, Huang YH, Hung SC. Allo-transplantation of mesenchymal stem cells attenuates hepatic injury through IL1Ra dependent macrophage switch in a mouse model of liver disease. J Hepatol. 2015;63(6):1405-1412.

77. Jackson MV, Morrison TJ, Doherty DF, et al. Mitochondrial transfer via tunneling nanotubes (TNT) is an important mechanism by which mesenchymal stem cells enhance macrophage phagocytosis in the in vitro and in vivo models of ARDS. Stem Cells. 2016;34(8): 2210-2223.

78. Abrams MB, Dominguez C, Pernold K, et al. Multipotent mesenchymal stromal cells attenuate chronic inflammation and injury-induced sensitivity to mechanical stimuli in experimental spinal cord injury. Restor Neurol Neurosci. 2009;27(4):307-321.

79. Le Blon D, Hoornaert C, Daans J, et al. Distinct spatial distribution of microglia and macrophages following mesenchymal stem cell implantation in mouse brain. Immunol Cell Biol. 2014;92(8):650-658.

80. Nakajima H, Uchida K, Guerrero AR, et al. Transplantation of mesenchymal stem cells promotes an alternative pathway of macrophage activation and functional recovery after spinal cord injury. $\mathrm{J} \mathrm{Neu-}$ rotrauma. 2012;29(8):1614-1625.

81. Watanabe S, Uchida K, Nakajima H, et al. Early transplantation of mesenchymal stem cells after spinal cord injury relieves pain hypersensitivity through suppression of pain-related signaling cascades and reduced inflammatory cell recruitment. Stem Cells. 2015;33(6):1902-1914.

82. Yin YM, Lu Y, Zhang LX, Zhang GP, Zhang ZQ. Bone marrow stromal cells transplantation combined with ultrashortwave therapy promotes functional recovery on spinal cord injury in rats. Synapse. 2015;69(3):139-147.

83. Seo JH, Jang IK, Kim H, et al. Early immunomodulation by intravenously transplanted mesenchymal stem cells promotes functional recovery in spinal cord injured rats. Cell Med. 2011;2(2): $55-67$.

84. Kim YH, Tabata Y. Recruitment of mesenchymal stem cells and macrophages by dual release of stromal cell-derived factor- 1 and a macrophage recruitment agent enhances wound closure. $J$ Biomed Mater Res A. 2016;104(4):942-956.

85. Kim J, Hematti P. Mesenchymal stem cell-educated macrophages: a novel type of alternatively activated macrophages. Exp Hematol. 2009;37(12):1445-1453.

86. Maggini J, Mirkin G, Bognanni I, et al. Mouse bone marrow-derived mesenchymal stromal cells turn activated macrophages into a regulatory-like profile. PLoS One. 2010;5(2):e9252.

87. Cho DI, Kim MR, Jeong HY, et al. Mesenchymal stem cells reciprocally regulate the M1/M2 balance in mouse bone marrow-derived macrophages. Exp Mol Med. 2014;46(1):e70.

88. Cao X, Han ZB, Zhao H, et al. Transplantation of mesenchymal stem cells recruits trophic macrophages to induce pancreatic beta cell regeneration in diabetic mice. Int J Biochem Cell Biol. 2014;53(8):372-379.
89. Choi H, Lee RH, Bazhanov N, Oh JY, Prockop DJ. Anti-inflammatory protein TSG- 6 secreted by activated MSCs attenuates zymosaninduced mouse peritonitis by decreasing TLR2/NF-kappaB signaling in resident macrophages. Blood. 2011;118(2):330-338.

90. Zhang B, Yin Y, Lai RC, Tan SS, Choo AB, Lim SK. Mesenchymal stem cells secrete immunologically active exosomes. Stem Cells Dev. 2014;23(11):1233-1244

91. Baglio SR, Rooijers K, Koppers-Lalic D, et al. Human bone marrowand adipose-mesenchymal stem cells secrete exosomes enriched in distinctive miRNA and tRNA species. Stem Cell Res Ther. 2015;6:127.

92. Ti D, Hao H, Tong C, et al. LPS-preconditioned mesenchymal stromal cells modify macrophage polarization for resolution of chronic inflammation via exosome-shuttled let-7b. J Transl Med. 2015;13:308.

93. Li M, Ikehara S. Bone-marrow-derived mesenchymal stem cells for organ repair. Stem Cells Int. 2013;2013:132642.

94. Greish S, Abogresha N, Abdel-Hady Z, Zakaria E, Ghaly M, Hefny M. Human umbilical cord mesenchymal stem cells as treatment of adjuvant rheumatoid arthritis in a rat model. World J Stem Cells. 2012;4(10):101-109.

95. Wang M, Yang Y, Yang D, et al. The immunomodulatory activity of human umbilical cord blood-derived mesenchymal stem cells in vitro. Immunology. 2009;126(2):220-232.

96. Krampera M, Pizzolo G, Aprili G, Franchini M. Mesenchymal stem cells for bone, cartilage, tendon and skeletal muscle repair. Bone. 2006;39(4):678-683.

97. Abumaree MH, Al Jumah MA, Kalionis B, et al. Human placental mesenchymal stem cells (pMSCs) play a role as immune suppressive cells by shifting macrophage differentiation from inflammatory $\mathrm{M} 1$ to antiinflammatory M2 macrophages. Stem Cell Rev. 2013;9(5):620-641.

98. Neirinckx V, Agirman G, Coste C, et al. Adult bone marrow mesenchymal and neural crest stem cells are chemoattractive and accelerate motor recovery in a mouse model of spinal cord injury. Stem Cell Res Ther. 2015;6:211.

99. Zhang J, Lu X, Feng G, et al. Chitosan scaffolds induce human dental pulp stem cells to neural differentiation: potential roles for spinal cord injury therapy. Cell Tissue Res. 2016;366(1):129-142.

100. Hwang I, Hahm SC, Choi KA, et al. Intrathecal transplantation of embryonic stem cell-derived spinal GABAergic neural precursor cells attenuates neuropathic pain in a spinal cord injury rat model. Cell Transplant. 2016;25(3):593-607.

101. Chen N, Cen JS, Wang J, et al. Targeted inhibition of leucine-rich repeat and immunoglobulin domain-containing protein 1 in transplanted neural stem cells promotes neuronal differentiation and functional recovery in rats subjected to spinal cord injury. Crit Care Med. 2016;44(3):e146-e157.

102. Yokota K, Kobayakawa K, Kubota K, et al. Engrafted neural stem/ progenitor cells promote functional recovery through synapse reorganization with spared host neurons after spinal cord injury. Stem Cell Reports. 2015;5(2):264-277.

103. Salewski RP, Mitchell RA, Shen C, Fehlings MG. Transplantation of neural stem cells clonally derived from embryonic stem cells promotes recovery after murine spinal cord injury. Stem Cells Dev. 2015;24(1):36-50.

104. Cusimano M, Biziato D, Brambilla E, et al. Transplanted neural stem/ precursor cells instruct phagocytes and reduce secondary tissue damage in the injured spinal cord. Brain. 2012;135(pt 2):447-460.

105. Nishimura S, Yasuda A, Iwai H, et al. Time-dependent changes in the microenvironment of injured spinal cord affects the therapeutic potential of neural stem cell transplantation for spinal cord injury. Mol Brain. 2013;6:3.

106. Busch SA, Hamilton JA, Horn KP, et al. Multipotent adult progenitor cells prevent macrophage-mediated axonal dieback and promote regrowth after spinal cord injury. J Neurosci. 2011;31(3):944-953.

107. Hasegawa K, Chang YW, Li H, et al. Embryonic radial glia bridge spinal cord lesions and promote functional recovery following spinal cord injury. Exp Neurol. 2005;193(2):394-410. 
108. Wang X, Chen T, Leng L, et al. MIF produced by bone marrow-derived macrophages contributes to teratoma progression after embryonic stem cell transplantation. Cancer Res. 2012;72(11):2867-2878.

109. Chen T, Wang X, Guo L, et al. Embryonic stem cells promoting macrophage survival and function are crucial for teratoma development. Front Immunol. 2014;5:275.

110. Nussbaum J, Minami E, Laflamme MA, et al. Transplantation of undifferentiated murine embryonic stem cells in the heart: teratoma formation and immune response. FASEB J. 2007;21(7):1345-1357.
111. Reubinoff BE, Pera MF, Fong CY, Trounson A, Bongso A. Embryonic stem cell lines from human blastocysts: somatic differentiation in vitro. Nat Biotechnol. 2000;18(4):399-404.

112. Swijnenburg RJ, Tanaka M, Vogel H, et al. Embryonic stem cell immunogenicity increases upon differentiation after transplantation into ischemic myocardium. Circulation. 2005;112(9 suppl):I166-I172.

113. Guo L, Rolfe AJ, Wang X, et al. Rescuing macrophage normal function in spinal cord injury with embryonic stem cell conditioned media. Mol Brain. 2016;9(1):48.
Journal of Neurorestoratology

\section{Publish your work in this journal}

The Journal of Neurorestoratology is an international, peer-reviewed, open access online journal publishing original research and review articles on the subject of Neurorestoratology. To provide complete coverage of this revolutionary field the Journal of Neurorestoratology will report on relevant experimental research, technological advances,
Dovepress

and clinical achievements. The manuscript management system is completely online and includes a very quick and fair peer-review system, which is all easy to use. Visit http://www.dovepress.com/testimonials. php to read real quotes from published authors. 